\title{
Variability of linezolid concentrations after standard dosing in critically ill patients: a prospective observational study
}

\author{
Michael Zoller ${ }^{1}$, Barbara Maier ${ }^{2}$, Cyrill Hornuss ${ }^{1}$, Christina Neugebauer ${ }^{1}$, Gundula Döbbeler ${ }^{1}$, Dorothea Nagel ${ }^{2}$, \\ Lesca Miriam Holdt², Mathias Bruegel ${ }^{2}$, Thomas Weig ${ }^{1}$, Béatrice Grabein ${ }^{3}$, Lorenz Frey ${ }^{1}$, Daniel Teupser ${ }^{2}$, \\ Michael Vogeser ${ }^{2}$ and Johannes Zander ${ }^{2 *}$
}

\begin{abstract}
Introduction: Severe infections in intensive care patients show high morbidity and mortality rates. Linezolid is an antimicrobial drug frequently used in critically ill patients. Recent data indicates that there might be high variability of linezolid serum concentrations in intensive care patients receiving standard doses. This study was aimed to evaluate whether standard dosing of linezolid leads to therapeutic serum concentrations in critically ill patients.

Methods: In this prospective observational study, 30 critically ill adult patients with suspected infections received standard dosing of $600 \mathrm{mg}$ linezolid intravenously twice a day. Over 4 days, multiple serum samples were obtained from each patient, in order to determine the linezolid concentrations by liquid chromatography tandem mass spectrometry.

Results: A high variability of serum linezolid concentrations was observed (range of area under the linezolid concentration time curve over 24 hours $\left(A \cup C_{24}\right) 50.1$ to $453.9 \mathrm{mg} / \mathrm{L}$, median $143.3 \mathrm{mg} / \mathrm{h} / \mathrm{L}$; range of trough concentrations $\left(C_{\min }\right)<0.13$ to $14.49 \mathrm{mg} / \mathrm{L}$, median $\left.2.06 \mathrm{mg} / \mathrm{L}\right)$. Furthermore, potentially subtherapeutic linezolid concentrations over 24 hours and at single time points (defined according to the literature as $\mathrm{AUC}_{24}<200 \mathrm{mg}$ *h/L and $\mathrm{C}_{\min }<2 \mathrm{mg} / \mathrm{L}$ ) were observed for $63 \%$ and $50 \%$ of the patients, respectively. Finally, potentially toxic levels (defined as $A \cup C_{24}>400 \mathrm{mg} / \mathrm{h} / \mathrm{L}$ and $C_{\min }>10 \mathrm{mg} / \mathrm{L}$ ) were observed for 7 of the patients.

Conclusions: A high variability of linezolid serum concentrations with a substantial percentage of potentially subtherapeutic levels was observed in intensive care patients. The findings suggest that therapeutic drug monitoring of linezolid might be helpful for adequate dosing of linezolid in critically ill patients.
\end{abstract}

Trial registration: Clinicaltrials.gov NCT01793012. Registered 24 January 2013.

\section{Introduction}

Severe infections in ICU patients remain a major challenge in modern medicine. The prevalence of severe infections such as sepsis or septic shock in ICU patients ranges from 20 to $80 \%$ with high mortality rates of 20 to $50 \%$ [1-5]. Consequently, there is a substantial need for optimizing antimicrobial therapy. Key elements for the treatment of infections include an adequate antimicrobial therapy with an early initiation and with sufficiently high drug

\footnotetext{
* Correspondence: Johannes.Zander@med.uni-muenchen.de

${ }^{2}$ Institute of Laboratory Medicine, Hospital of the Ludwig-Maximilians-University of Munich, Marchioninistrasse 15, Munich 81377, Germany

Full list of author information is available at the end of the article
}

concentration levels [6-10]. Furthermore, sufficiently high drug concentrations are required to limit the development of antimicrobial resistance [11].

About 50\% of bloodstream infections in critically ill patients are caused by Gram-positive bacteria [12,13]. A major part of these Gram-positive infections are represented by multidrug-resistant strains (for example, methicillin-resistant Staphylococcus aureus (MRSA) and vancomycin-resistant enterococci (VRE)), which are particularly frequent in ICUs [12-17]. Linezolid has good in vitro and in vivo activity against these organisms and is

C Biomed Central

(c) 2014 Zoller et al.; licensee BioMed Central Ltd. This is an Open Access article distributed under the terms of the Creative Commons Attribution License (http://creativecommons.org/licenses/by/4.0), which permits unrestricted use, distribution, and reproduction in any medium, provided the original work is properly credited. The Creative Commons Public Domain Dedication waiver (http://creativecommons.org/publicdomain/zero/1.0/) applies to the data made available in this article, unless otherwise stated. 
an important antibiotic for the treatment of infections in critically ill patients $[9,16,18-22]$. The volume of distribution in adults of this hydrophilic antibiotic approximates to the total body water content of 40 to $60 \mathrm{~L}$ [23]. The plasma elimination half-life is mostly reported to be between 3.1 and $4.9 \mathrm{~h}$ with a clearance rate between 6.4 and $14.8 \mathrm{~L} / \mathrm{h}$ [23]. Linezolid is metabolized by liver enzymes to two major inactive metabolites, an aminoethoxyacetic acid and a hydroxyethyl glycine, which are excreted predominantly - together with the parent substance - in urine [24,25]. Because of its intrinsic chemico-physical and pharmacokinetic characteristics, it is assumed that adequate serum linezolid concentrations will be achieved most of the time when using the recommended dose of $600 \mathrm{mg}$ every 12 hours and that therapeutic drug monitoring (TDM) might not be necessary [26,27]. This assumption is based on reports showing adequate linezolid concentrations in healthy volunteers or non-critically ill patients [27-29]. According to the manufacturer, no dose adjustment of linezolid is necessary in the case of renal or liver impairment. Consequently, expert panels recommend standardized doses of $600 \mathrm{mg}$ linezolid twice a day also for patients with severe infections such as sepsis or septic shock [30]. However, 10 to $30 \%$ of critically ill patients receiving linezolid have treatment failure despite isolation of Gram-positive organisms sensitive to linezolid [16,31,32]. Of these, 15 to $30 \%$ of patients suffer furthermore from adverse effects such as elevated liver enzymes, gastrointestinal disturbances or hematological toxicity [32-34]. The rate of therapy failure and adverse effects may be in part explained by a high variability of linezolid serum concentrations in critically ill patients.

Though there are have been few studies evaluating blood levels and pharmacokinetic parameters of linezolid in critically ill patients [26,35-41], it is still very difficult for physicians to decide if therapeutic levels are reached after standard dosing with linezolid when treating critically ill patients. The studies to date have found variable results with regard to linezolid blood levels. A substantial number demonstrated that inadequate levels occur $[36,37,39,41]$ whereas others concluded that standard doses are mostly sufficient [35,38]. Low numbers of study patients, the lack of use of compartment models, and the retrospective design of most studies leave inconclusive information about this topic within the existing literature. Moreover, there are only preliminary data for linezolid blood levels in specific subgroups of ICU patients, such as critically ill patients on continuous renal replacement therapy (CRRT), those on extracorporeal lung assist (ECLA) and patients who have undergone organ transplantation $[41,42]$. Indeed, most of these studies excluded particular patient groups, therefore, do not represent the full spectrum of different patients in ICUs. We therefore designed a prospective observational study to analyze the variability of linezolid serum concentrations in relation to preliminary target concentration ranges in a heterogeneous group of critically ill patients with suspected infections. The primary aim of the study was to evaluate whether linezolid serum concentrations in different critically ill patients were within the defined therapeutic range.

\section{Materials and methods \\ Patients}

The study population originated from medical-surgical critically ill patients hospitalized in two ICUs within the Department of Anesthesiology, University Hospital of Munich between March and November 2013. Patients were eligible for inclusion if they had a severe infection (confirmed or suspected by clinical assessment) and were treated with linezolid intravenously by short-duration infusions according to the clinic guidelines, and in accordance with the German Paul-Ehrlich-Society and the guidelines of the Infectious Disease Society of America $[30,43]$. Patients were only excluded if they were under the age of 18 years, if their planned hospitalization was less than 4 days, or if the first linezolid administration was given more than $48 \mathrm{~h}$ before study enrollment. Written informed consent was obtained from all patients or their legal representatives.

\section{Study design}

The monocentric, prospective observational study was performed at the University Hospital of Munich. The study protocol (ClinicalTrials.gov, NCT01793012) was approved by the Institutional Review Board of the Medical Faculty of the Ludwig-Maximilians-University (registration number 428-12) and carried out according to the principles of the Declaration of Helsinki. Enrolled patients $(\mathrm{n}=30)$ received $600 \mathrm{mg}$ linezolid twice a day by short-duration infusion (15 to 60 minutes). Day 1 of the study was defined as that day on which the first linezolid trough level $\left(\mathrm{C}_{\mathrm{min}}\right)$ was determined (see Additional file 1). This was directly before the second or third linezolid administration in all patients except patients 2 and 27, for whom the study start was directly before the fifth and fourth linezolid administration, respectively. Serum samples from the arterial line for antibiotic determination were collected at multiple time points before $\left(\mathrm{C}_{\min }\right)$, during, and after the two linezolid administrations on day 1 ; and before, during, and after one of the two linezolid administrations on days 2, 3 and 4 (in total 26 to 43 samples per patient). The exact time of blood sampling was recorded by the medical staff. Samples were immediately sent to the Institute of Laboratory Medicine, University Hospital of Munich, centrifuged (3,000 g, 10 minutes) and aliquoted into 2-ml polypropylene tubes (Eppendorf, Hamburg, Germany). Serum aliquots were stored within one hour after blood sampling at $-80^{\circ} \mathrm{C}$. 


\section{Determination of clinical and laboratory parameters}

Clinical patient data and diagnosis in the ICU were recorded. Sepsis was defined according to the Society of Critical Care Medicine/European Society of Intensive Care Medicine (SCCM/ESICM) Consensus Conference Committee [10]. The severity of the patient's clinical condition was characterized using the acute physiology and chronic health evaluation (APACHE) II score. To assess renal function, creatinine concentrations in both serum and 24-h urine samples were determined using an enzymatic photometric test on an automated chemistry analyzer (Model AU5822: Beckmann Coulter, Brea, CA, USA). Creatinine clearance $\left(\mathrm{CL}_{\text {crea }}\right)$ was calculated using the formula:

$$
\mathrm{CL}_{\text {crea }}=\left(\mathrm{C}_{\text {urine }} * \mathrm{~V}_{\text {urine }}\right):\left(\mathrm{C}_{\text {serum }} * \text { time }\right),
$$

where $\mathrm{C}_{\text {urine }}$ is the creatinine concentration in urine, $V_{\text {urine }}$ is the urine volume, and $C_{\text {serum }}$ is the serum creatinine concentration.

\section{Determination of linezolid concentrations}

Serum linezolid concentrations were determined using a previously described liquid chromatography tandem mass spectrometry (LC-MS/MS) method [44]. Briefly, sample preparation was based on protein precipitation and on-line solid phase extraction with two-dimensional liquid chromatography and column switching. Three-fold deuterated linezolid was used as the internal standard. Control samples were used from both a commercial provider and from inhouse production. Validation revealed good analytical performance showing inaccuracy $<6 \%$ and imprecision $<7.3 \%$ (coefficient of variation) for all quality control samples. The lower limit of quantification was $0.13 \mathrm{mg} / \mathrm{L}$. The method was found to be robust over the course of the study.

\section{Pharmacokinetic analysis}

We analyzed linezolid plasma concentrations with a compartmental pharmacokinetic model based on nonlinear mixed-effects modeling. For model estimation we used the NONMEM $7.2^{\circ}$ program (Icon Development Solutions, Hanover, MD, USA) with the FOCE-I estimation algorithm. The aim of the pharmacokinetic analysis was to determine individual concentration time courses. We assumed that the population parameters were log-normally distributed. The individual post-hoc concentration predictions obtained from NONMEM were used to predict the time course of linezolid plasma concentrations and to calculate the area under the concentration time curve over $24 \mathrm{~h}\left(\mathrm{AUC}_{24}\right)$-values. Model selection was based on the NONMEM objective function, goodness-of-fit plots, and median absolute performance errors as described by Varvel et al. [45]. For graphical analysis we used PLTTools 5.0 PLTsoft, San Francisco, CA USA [46]. Linezolid plasma concentrations were calculated for each patient based on individual pharmacokinetic parameters in 10-minute steps.

\section{Assessment of target concentration ranges}

The thresholds for potential therapeutic efficacy were defined as $\mathrm{C}_{\min }>2 \mathrm{mg} / \mathrm{L}$ and/or $\mathrm{AUC}_{24}>200 \mathrm{mg}$ *h/L. The rationale behind these two thresholds was the findings of Rayner et al., showing a higher therapeutic success in seriously ill patients when linezolid exceeds the minimum inhibitory concentration (MIC) over the entire dosing interval or when $\mathrm{AUC}_{24} / \mathrm{MIC}$-values are higher than 80 to 120 [31]. We defined the MIC as the concentration that inhibits the growth of $90 \%$ of important relevant infectious pathogens $\left(\mathrm{MIC}_{90}\right)$ (particularly S. aureus and Enterococcus species) $[47,48]$ and therefore, we set the threshold of potential therapeutic efficacy of $C_{\min }$ at $2 \mathrm{mg} / \mathrm{L}$. As in Rayner et al., we set the $\mathrm{AUC}_{24} / \mathrm{MIC}_{90}$ value at 100 , corresponding to a threshold for potential therapeutic efficacy of $\mathrm{AUC}_{24}$-values of $200 \mathrm{mg}$ *h/L. The threshold for potential therapeutic toxicity was defined as trough levels $>10 \mathrm{mg} / \mathrm{L}$ or $\mathrm{AUC}_{24}$ values $>400 \mathrm{mg}$ "h/L according to the literature $[23,26,34]$.

\section{Statistics}

The $\mathrm{AUC}_{24}$ was calculated by means of the trapezoidal rule using concentration values as predicted by the pharmacokinetic model (individual post-hoc concentration time course). Patients were divided into three groups in relation to the defined target concentration ranges based on their $\mathrm{C}_{\mathrm{min}^{-}}$and $\mathrm{AUC}_{24}$-values. Non-continuous parameters were expressed as percentages and numbers, and compared by means of the Chi-square test. Continuous parameters were expressed as median values and ranges, and compared by the Jonckheere-Terpstra test. A $P$-value below 0.05 was considered statistically significant. All calculations were performed using SAS (version 9.3, SAS Institute Inc., Cary, NC, USA).

\section{Results}

Twenty male and ten female patients with a median age of 57 years (range, 28 to 84 years) and a median body mass index (BMI) of $25.5 \mathrm{~kg} / \mathrm{m}^{2}$ (range, 16 to $35 \mathrm{~kg} / \mathrm{m}^{2}$ ) were included. The most frequent causes of sepsis were pneumonia and peritonitis (Table 1). Ten patients were lung-transplant, and five were liver-transplant recipients. Patients had high variability in APACHE II scores (range 9 to 37, median 27.5). Of the 25 patients who were not on CRRT, 5 had a reduced creatinine clearance of $<50 \mathrm{ml} /$ minute. Five patients were being treated with CRRT and seven patients were treated with ECLA. Detailed parameters of the corresponding CRRT and ECLA systems are shown in Additional files 2 and 3.

Linezolid plasma concentrations were best described by a two-compartment model with an individual (post-hoc) 
Table 1 Characteristics of the study population

\begin{tabular}{|c|c|c|c|c|c|c|}
\hline Patient number & $\begin{array}{l}\text { APACHE II } \\
\text { score }\end{array}$ & $\begin{array}{l}\text { Mean creatinine } \\
{\text { clearance }(\mathrm{ml} / \text { minute })^{\mathrm{a}}}\end{array}$ & CRRT (+/-) & ECLA (+/-) & Organ transplantation $^{\mathbf{b}}$ & Clinical condition \\
\hline 1 & 20 & 89 & - & + & Lung & Septic pneumonia \\
\hline 2 & 12 & 129 & - & - & - & ARDS \\
\hline 3 & 20 & 21 & - & - & - & Septic peritonitis \\
\hline 4 & 28 & 114 & - & - & - & Septic pleural empyema \\
\hline 5 & 23 & 97 & - & + & - & ARDS \\
\hline 6 & 33 & 72 & - & + & - & Septic pneumonia \\
\hline 7 & 9 & 117 & - & - & Lung & Septic pneumonia \\
\hline 8 & 28 & 119 & - & - & Lung & Septic pneumonia \\
\hline 9 & 28 & - & + & - & Liver & Septic peritonitis \\
\hline 10 & 29 & 94 & - & - & - & Septic pneumonia \\
\hline 11 & 33 & 35 & - & - & Lung & Septic pneumonia \\
\hline 12 & 31 & 102 & - & + & - & Septic pneumonia \\
\hline 13 & 14 & 127 & - & - & - & Septic pneumonia \\
\hline 14 & 14 & 69 & - & - & Lung & Septic pneumonia \\
\hline 15 & 32 & 42 & - & - & - & Septic endocarditis \\
\hline 16 & 19 & 76 & - & + & - & Septic pneumonia \\
\hline 17 & 35 & - & + & - & Liver & Septic peritonitis \\
\hline 18 & 21 & 33 & - & - & Lung & Septic pneumonia \\
\hline 19 & 27 & 55 & - & - & Lung & Septic pneumonia \\
\hline 20 & 17 & 64 & - & - & Lung & Septic pleural empyema \\
\hline 21 & 30 & 68 & - & - & - & Septic pneumonia \\
\hline 22 & 23 & - & + & - & Liver & Septic peritonitis \\
\hline 23 & 14 & 85 & - & - & Liver & Septic peritonitis \\
\hline 24 & 24 & - & + & - & Liver & Septic peritonitis \\
\hline 25 & 37 & 74 & - & - & Lung & Septic pneumonia \\
\hline 26 & 25 & 83 & - & + & Lung & Septic pneumonia \\
\hline 27 & 28 & - & + & - & - & Septic peritonitis \\
\hline 28 & 34 & 163 & - & + & - & Septic pneumonia \\
\hline 29 & 32 & 126 & - & - & - & ARDS \\
\hline 30 & 29 & 37 & - & - & - & Septic peritonitis \\
\hline Median & 27.5 & 83 & & & & \\
\hline (range) & (9 to 37 ) & (21 to 163 ) & & & & \\
\hline
\end{tabular}

${ }^{a}$ Mean value of the 4 study days; ${ }^{b}$ within the last 28 days. APACHE II, acute physiology and chronic health evaluation II score; CRRT, continuous renal replacement therapy; ECLA, extracorporeal lung assist; ARDS, acute respiratory distress syndrome.

median prediction error of $1 \%$ and a median absolute prediction error of $13 \%$. The parameter estimates (standard error) of the population model were: volume of distribution of the first compartment $=19.3$ (3.9) L, volume of distribution of the second compartment $=26.4(3.8) \mathrm{L}$, elimination clearance $=8.3(0.9) \mathrm{L} / \mathrm{h}$ and inter-compartmental clearance $=56.0(19.3) \mathrm{L} / \mathrm{h}$.

Figure 1 shows the concentration time curves of serum linezolid for each patient. A high inter-patient variability was observed. The high inter-patient variability could be quantified when $\mathrm{AUC}_{24}$-values ranged from 50.1 to $453.9 \mathrm{mg}^{*} \mathrm{~h} / \mathrm{L}$ (median $143.3 \mathrm{mg}^{*} \mathrm{~h} / \mathrm{L}$ ) (Table 2). The high inter-patient variability was also observed for single $\mathrm{C}_{\text {min }}$-values (range $>100$-fold, from $<0.13$ to $14.49 \mathrm{mg} / \mathrm{L}$, median $2.06 \mathrm{mg} / \mathrm{L}$ ) (Table 2). To obtain further information about the usefulness of $\mathrm{c}_{\min }$-values for TDM, $\mathrm{C}_{\text {min }}$ values were correlated with corresponding $\mathrm{AUC}_{24}$ values giving an $r^{2}$ value of 0.79 (Additional file 4).

In addition to the inter-patient variability, high intrapatient variability of $C_{\min }$ values was also observed. Nine of thirty patients had maximum $\mathrm{C}_{\min }$ values, more than 5-fold higher than the minimum $\mathrm{C}_{\min }$ values (range of 


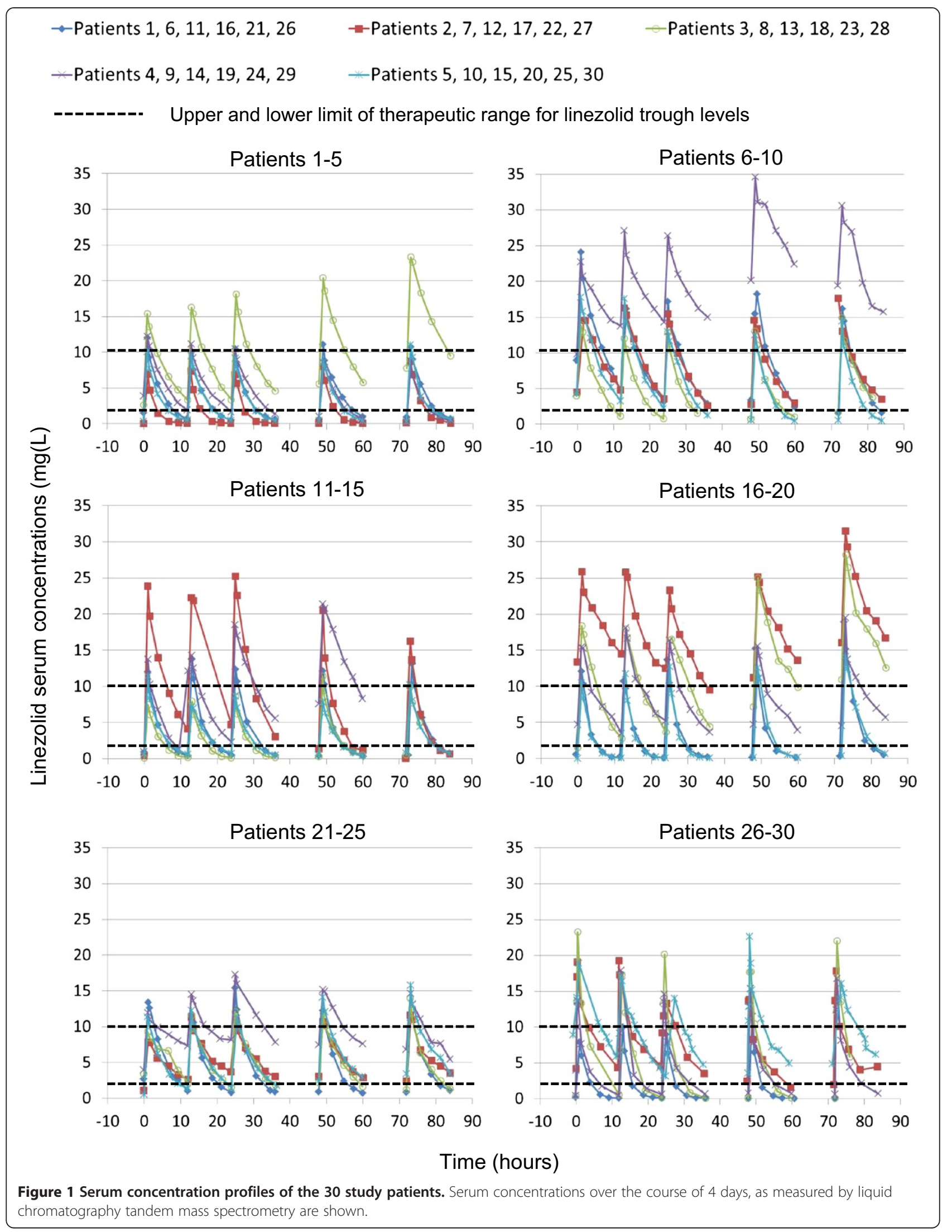


Table 2 Linezolid pharmacokinetic parameters following intravenous administration of $600 \mathrm{mg}$ twice daily in critically ill ICU patients

\begin{tabular}{|c|c|c|}
\hline Patient number & $\mathrm{AUC}_{24}\left(\mathrm{mg} \mathrm{g}^{*} \mathrm{~h} / \mathrm{L}\right)^{\mathrm{a}}$ & $C_{\min }(m g / L)^{b}$ \\
\hline 1 & 99.1 & 0.67 \\
\hline 2 & 50.1 & $<0.13^{c}$ \\
\hline 3 & 258.2 & 3.35 \\
\hline 4 & 118.3 & 1.89 \\
\hline 5 & 82.3 & 0.46 \\
\hline 6 & 213.7 & 3.15 \\
\hline 7 & 206.3 & 3.59 \\
\hline 8 & 138.9 & 1.17 \\
\hline 9 & 453.9 & 13.75 \\
\hline 10 & 165.3 & 3.26 \\
\hline 11 & 105.3 & 0.43 \\
\hline 12 & 224.7 & 4.13 \\
\hline 13 & 67.6 & 0.14 \\
\hline 14 & 266.9 & 2.31 \\
\hline 15 & 80.8 & 0.70 \\
\hline 16 & 101.7 & 0.18 \\
\hline 17 & 442.0 & 14.49 \\
\hline 18 & 325.6 & 2.75 \\
\hline 19 & 217.8 & 3.48 \\
\hline 20 & 94.8 & $<0.13$ \\
\hline 21 & 122.0 & 1.03 \\
\hline 22 & 144.6 & 3.70 \\
\hline 23 & 141.8 & 2.22 \\
\hline 24 & 250.8 & 8.18 \\
\hline 25 & 157.1 & 1.45 \\
\hline 26 & 50.8 & $<0.13$ \\
\hline 27 & 165.1 & 4.22 \\
\hline 28 & 106.2 & 0.17 \\
\hline 29 & 86.5 & 0.45 \\
\hline 30 & 244.1 & 5.86 \\
\hline Median & 143.3 & 2.06 \\
\hline Range & 50.1 to 453.9 & $<0.13$ to 14.49 \\
\hline
\end{tabular}

${ }^{a}$ As determined by the NONMEM system, values from the start of the third administration of linezolid over $24 \mathrm{~h}$; ${ }^{\text {bas }}$ analyzed by liquid chromatography tandem mass spectrometry, values obtained directly before the fourth administration of linezolid if not indicated otherwise;

cvalue obtained directly before the fifth administration of linezolid. $A U C_{24}$, concentration time curve over $24 \mathrm{~h} ; \mathrm{C}_{\text {min, }}$ linezolid trough level.

maximum/minimum $C_{\min }$ values 1 to 36 ) (Figure 1; see also Additional file 5). The $\mathrm{C}_{\min }$ of most patients did not change in a consistent pattern over the 4 days of the study; only in patients 3,14, 18 and 25 did we observe an increase, and in patient 4 a decrease of $C_{\min }$ values over time (Figure 1).
Optimal pharmacodynamic exposure over $24 \mathrm{~h}$ with $\mathrm{AUC}_{24}$ values between 200 and $400 \mathrm{mg}$ "h/L and at a single time point with $\mathrm{C}_{\min }$ values between 2 and $10 \mathrm{mg} / \mathrm{L}$ was observed in $30 \%$ and $43 \%$ of the patients, respectively (Table 3, Figure 1). Regarding these $\mathrm{AUC}_{24}$ and $\mathrm{C}_{\text {min }}$ values, $63 \%$ and $50 \%$ of the study patients had linezolid concentrations below the lower limit of the corresponding target concentration range, respectively, and 7\% had linezolid concentrations above the target concentration range. Moreover, only $17 \%$ of the patients continuously attained optimal $\mathrm{C}_{\min }$ values between 2 and $10 \mathrm{mg} / \mathrm{L}$ over 4 days (see Additional file 5).

Patients on CRRT had significantly higher $C_{\min }$ values and $\mathrm{AUC}_{24}$ values than patients without CRRT $(P=0.005$ for $\mathrm{AUC}_{24}$ and $P=0.001$ for $C_{\text {min }}$ ) (Table 3). Similarly, patients who had undergone liver transplantation had significantly higher $\mathrm{AUC}_{24}$ and $\mathrm{C}_{\text {min }}$ values than in non- (liver and lung) transplant patients $(P=0.036$ for AUC $_{24}$ and $P=0.012$ for $C_{\text {min }}$ ). Other characteristics such as gender, lung transplantation and therapy with ECLA did not have any significant influence on $\mathrm{AUC}_{24}$ or $\mathrm{C}_{\min }$ values. Variability of linezolid levels was high in patient groups on CRRT and ECLA, and in the liver and lung transplantation groups, with each group showing a substantial proportion $(\geq 40 \%)$ outside the target concentration range. The distributions of continuous parameters in relation to linezolid target ranges are shown in Table 4. A trend towards higher linezolid serum levels was observed in patients with reduced creatinine clearance, although these changes were not significant $\left(P=0.102\right.$ for $C_{\min }$ and $P=0.051$ for $\mathrm{AUC}_{24}$ ) (Table 4 , Additional file 6). Other continuous parameters such as age, BMI, and APACHE-II score did not have any significant influence on $\mathrm{AUC}_{24}$ or $\mathrm{C}_{\text {min }}$ values.

\section{Discussion}

This study shows that the recommended standard dosing of linezolid leads to subtherapeutic linezolid plasma concentrations in about every second critically ill patient. Furthermore, a high variability of linezolid levels was observed in the study population with a majority (57 to $70 \%$ ) detected outside the target ranges. Although there were insufficient levels in the majority of patients, inappropriate high levels occurred in a small number of patients. Finally, this variability of linezolid levels was not only observed between the different patients, but also within individual patients over the course of 4 days.

Our findings are in line with other studies also observing very low $\mathrm{AUC}_{24}$ or $\mathrm{C}_{\text {min }}$ values with the majority being insufficient $[37,39,41]$. In contrast to some other studies $[37,39]$, we used two different approaches to define the lower threshold of the target range. First, we used $\mathrm{AUC}_{24} / \mathrm{MIC}$ in concordance with other studies $[26,35,36,38,40,41]$, which was shown to be the best 
Table 3 Distribution of patients in relation to the target range of linezolid

\begin{tabular}{|c|c|c|c|c|c|c|}
\hline \multirow{3}{*}{$\begin{array}{l}\text { Patient groups, number } \\
\text { of patients }\end{array}$} & \multicolumn{6}{|c|}{ Number (percentage) of linezolid patients } \\
\hline & \multicolumn{3}{|c|}{$\mathrm{AUC}_{24}, \mathrm{mg} \mathrm{F}^{*} / \mathrm{L}^{\mathrm{a}}$} & \multicolumn{3}{|c|}{$\mathrm{C}_{\min }, \mathrm{mg} / \mathrm{L}^{\mathrm{b}}$} \\
\hline & $<200$ & 200 to 400 & $>400$ & $<2$ & 2 to 10 & $>10$ \\
\hline Total patients, $n=30$ & $19(63)$ & $9(30)$ & $2(7)$ & $15(50)$ & $13(43)$ & $2(7)$ \\
\hline Male patients, $\mathrm{n}=20^{c}$ & $13(65)$ & $5(25)$ & $2(10)$ & $11(55)$ & $7(35)$ & $2(10)$ \\
\hline Female patients, $n=10$ & $6(60)$ & $4(40)$ & & $4(40)$ & $6(60)$ & \\
\hline On CRRT, $n=5^{d}$ & $2(40)$ & $1(20)$ & $2(40)$ & & $3(60)$ & $2(40)$ \\
\hline Not on CRRT, $n=25$ & $17(68)$ & $8(32)$ & & $15(60)$ & $10(40)$ & \\
\hline On ECLA, $n=7^{c}$ & $5(71)$ & $2(29)$ & & $5(71)$ & $2(29)$ & \\
\hline Not on $\mathrm{ECLA}, \mathrm{n}=23$ & $14(61)$ & $7(30)$ & $2(9)$ & $10(43)$ & $11(48)$ & $2(9)$ \\
\hline After liver transplantation, $n=5^{f}$ & $2(40)$ & $1(20)$ & $2(40)$ & & $3(60)$ & $2(40)$ \\
\hline After lung transplantation, $\mathrm{n}=10^{\mathrm{c}}$ & $6(60)$ & $4(40)$ & & $6(60)$ & $4(40)$ & \\
\hline No transplantation, $\mathrm{n}=15$ & $11(73)$ & $4(27)$ & & $9(60)$ & $6(40)$ & \\
\hline
\end{tabular}

${ }^{a}$ As determined by the NONMEM system, values from the start of the third administration of linezolid; bas determined by liquid chromatography tandem mass spectrometry, values obtained directly before the fourth administration of linezolid; ' no significantly different values in comparison to the corresponding patient

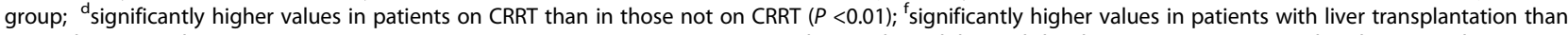
in non-liver-transplant patients $(P<0.05)$. $A_{U} C_{24}$, concentration time curve over $24 \mathrm{~h} ; \mathrm{C}_{\min }$, linezolid trough level; CRRT, continuous renal replacement therapy; ECLA, extracorporeal lung assist.

parameter to predict efficacy [31]. When we used this approach $63 \%$ of our study patients had insufficient linezolid serum levels. Second, we used $\mathrm{C}_{\min }$ values as a further lower threshold of the target concentration range, as time above the MIC over the entire dosing interval also correlates with efficacy [31]. This value was set at $2 \mathrm{mg} / \mathrm{L}$ in accordance with $\mathrm{MIC}_{90}$ values of relevant causative pathogens $[47,48]$ as had been done in other studies $[26,37,39]$. Different efficacy thresholds might be used in environments where $\mathrm{MIC}_{90}$ values of relevant pathogens differ from $2 \mathrm{mg} / \mathrm{L}$. Indeed, linezolid serum concentrations during infection should

Table 4 Distributions of continuous parameters in relation to linezolid target ranges

\begin{tabular}{|c|c|c|c|c|c|c|}
\hline \multirow[b]{3}{*}{ Patient groups } & \multicolumn{6}{|c|}{ Median and range of patients } \\
\hline & \multicolumn{3}{|c|}{$\mathrm{AUC}_{24}\left(\mathrm{mg} \mathrm{g}^{*} \mathrm{~h} / \mathrm{L}\right)^{\mathrm{a}}$} & \multicolumn{3}{|c|}{$C_{\min }(\mathrm{mg} / \mathrm{L})^{b}$} \\
\hline & $<200$ & 200 to 400 & $>400$ & $<2$ & 2 to 10 & $>10$ \\
\hline \multicolumn{7}{|c|}{$\overline{\text { Mean creatinine clearance }(\mathrm{mL} / \text { minute })^{c}}$} \\
\hline median & 89 & 62 & & 89 & 70 & \\
\hline range & 35 to 163 & 21 to 117 & & 35 to 163 & 21 to 117 & \\
\hline (number of patients) & (17) & (8) & & (15) & (10) & \\
\hline \multicolumn{7}{|l|}{ APACHE II score } \\
\hline median & 28 & 24 & 32 & 28 & 24 & 32 \\
\hline range & 12 to 37 & 9 to 33 & 28 to 35 & 12 to 37 & 9 to 33 & 28 to 35 \\
\hline (number of patients) & (19) & (9) & (2) & (15) & (13) & (2) \\
\hline \multicolumn{7}{|l|}{ Age (years) } \\
\hline median & 53 & 59 & 56 & 57 & 57 & 56 \\
\hline range & 28 to 77 & 34 to 84 & 50 to 61 & 28 to 77 & 29 to 84 & 50 to 61 \\
\hline (number of patients) & (19) & (9) & (2) & (15) & (13) & (2) \\
\hline \multicolumn{7}{|l|}{ Body mass index $\left(\mathrm{kg} / \mathrm{m}^{2}\right)$} \\
\hline median & 24 & 19 & 21 & 22 & 23 & 21 \\
\hline range & 13 to 32 & 17 to 26 & 19 to 23 & 13 to 32 & 17 to 28 & 19 to 23 \\
\hline (number of patients) & (19) & (9) & (2) & (15) & (13) & (2) \\
\hline
\end{tabular}


reach sufficient levels for most causative pathogens to ensure efficacy. This might be particularly important, as the identity of most causative pathogens is unknown in the early course of severe infection.

Furthermore, we showed that there is a high variability of linezolid $\mathrm{AUC}_{24}$ and $\mathrm{C}_{\text {min }}$ values with $\mathrm{C}_{\text {min }}$ values differing more than 100-fold between the different study patients and more than 30 -fold within individual patients. This is in line with some recent studies also describing high variability of $C_{\min }$ values differing more than 50 -fold between different patients $[26,34,41]$. In fact, the majority of linezolid concentrations in our study was outside the defined linezolid target concentration ranges, supporting the concept of TDM. We set the upper threshold of the target concentration range for $C_{\min }$ values at $10 \mathrm{mg} / \mathrm{L}$. This was done in accordance with other studies, because higher concentrations have been shown to be associated with drug-related toxicity $[23,26,34]$, whereas Pea at al. showed that in long-term treatment with linezolid an upper threshold of the target concentration range of $7 \mathrm{mg} / \mathrm{L}$ should be favored [49]. Indeed, in the study of Pea et al., all patients with $\mathrm{C}_{\min }$ values $>10 \mathrm{mg} / \mathrm{L}$ of linezolid had substantial platelet reduction $(>30 \%)$ during longterm linezolid treatment, whereas no patient had these adverse effects with $C_{\min }$ values $<4 \mathrm{mg} / \mathrm{L}$. Despite the rather high upper threshold used in our study, $7 \%$ of the patients had linezolid concentrations above the target range. The fact that for critically ill patients, the two parameters $\mathrm{AUC}_{24} / \mathrm{MIC}>80$ to 120 and time above MIC over the entire dosing interval strongly correlated with treatment efficacy [31], and that elevated linezolid concentrations correlated with adverse effects [23,34], show that both $\mathrm{AUC}_{24}$ and $\mathrm{C}_{\min }$ values correlate with efficacy and toxicity. This strongly supports the concept of linezolid target concentration ranges in terms of TDM. The good linear relationship between $\mathrm{C}_{\text {min }}$ and $\mathrm{AUC}_{24}$ values described by Pea et al. [26] was confirmed in our study $\left(r^{2}=0.79\right)$. $\mathrm{C}_{\text {min }}$ might therefore be a useful parameter for TDM of linezolid in clinical practice. As a high variation of $\mathrm{C}_{\mathrm{min}}$ values within individual patients was observed in this study, we would recommend repetitive determinations of linezolid $\mathrm{C}_{\min }$ values during infection treatment.

Finally, the linezolid serum concentrations in different critically ill patients, such as those on CRRT or ECLA, and patients who had undergone liver or lung transplantation, were evaluated. Only a few studies have evaluated the pharmacokinetics of linezolid in critically ill patients on CRRT [50-53], thereby using different CRRT systems such as continuous venovenous hemodiafiltration (CVVHDF) and continuous venovenous hemofiltration $(\mathrm{CVVH})$. Linezolid concentrations were partly subtherapeutic and partly within the potential therapeutic range, however, a comparison of linezolid levels in patients not on CRRT was not performed. In our study, linezolid concentrations were tested in patients with CVVHDF and CVVHD. In comparison to the other study patients, significantly higher linezolid levels were observed in patients on CRRT. However, it should be noted that four of the five patients on CRRT were liver transplant recipients and that higher levels of linezolid have been reported in patients after liver transplantation [41]. About $50 \%$ of the parent substance linezolid is metabolized by liver enzymes to two major inactive metabolites and are excreted predominantly - together with linezolid - in urine [25]. Higher levels of linezolid in patients after liver transplantations might therefore be due to alterations in the activity of liver enzymes after ischemia/reperfusion [41]. Higher numbers of patients on CRRT and those after liver transplantations with simultaneous evaluation of the liver function, as well as of linezolid and its inactive metabolites in urine will be necessary to definitely understand the impact of CRRT and liver transplantations on linezolid concentrations in critically ill patients. Furthermore, we evaluated linezolid levels in patients after lung transplantation and patients on ECLA, and no significant differences (in the setting used in our study) in comparison to the whole study population were observed. Admittedly, the majority of the linezolid levels were also insufficient in these patients. This is in line with the reported low linezolid levels in three critically ill patients on extracorporeal membrane oxygenationsystems (specific ECLA system) and three critically ill patients after lung transplantation [42,50], which are the only available data on these patients.

The results of this study suggest that the limited availability of linezolid quantification methods in clinical laboratories might pose a serious problem for the antimicrobial therapy of ICU patients. The reason for the limited availability of such methods is in particular the lack of cost-efficient commercially available linezolid quantification tests. Only a few laboratories use custommade linezolid quantification methods such as high performance liquid chromatography with UV-detection (HPLC-UV) or LC-MS/MS. Development and routine use of these custom-made methods require a high level of human resources, professional specialization and hightechnology equipment, which can often only be provided by large or specialized laboratories. The availability of commercial quantification tests (for example, based on HPLC-UV or immunoassay methods) of a therapeutic substance applied in life-threatening conditions might therefore be of particular impact.

The present study considered a number of aspects which have only partially been covered in previous work: (a) we investigated numerous critically ill patients from the whole intensive care spectrum, including patients who had undergone lung and liver transplantation and during CRRT and ECLA; (b) we analyzed a large number of 
linezolid plasma samples. This allowed description of individual concentration time courses by pharmacokinetic modeling with a small median prediction error of $1 \%$ and a small median absolute prediction error of $13 \%$; (c) finally, this study used a highly accurate method for linezolid quantification [44]. All other studies measuring linezolid concentrations in critically ill patients used HPLC-UV [26,35-41], which may be prone to interference, especially in critically ill patients with extended co-medication. In contrast, we used an LC-MS/MS method, thereby, for the first time, using isotope dilution internal standardization. As target analytes and internal standards are very similar in their physico-chemical properties, variances of individual samples impacting the ionization are compensated almost completely, realizing the highest attainable level of reliability [54]. Furthermore, the use of control samples from both a commercial provider and from in-house production additionally ensures the accuracy of the method. Indeed, there were only minimal undulations in the concentration-time curves of linezolid in individual patients (Figure 1), showing that the study-protocol, including blood sampling and analytical method, was accurately performed.

The high variability of linezolid levels found in our study, with a substantial proportion at insufficient low levels, might contribute to the observed high mortality rate and severity of infection in ICU patients. Furthermore, high variability of linezolid levels may also lead to the development of resistance and drug-related toxicity. As early and effective antimicrobial therapy has a substantial effect on bacterial eradication and patient survival [6,31], optimal individual dosing of antibiotics is of particular importance. Given the fact that the most common cause of death in the ICU in medically advanced nations is severe infection [55] and because of worldwide intentions to reduce morbidity and mortality from sepsis [10], we believe that there is great importance in optimizing individual antimicrobial dosing with the aid of TDM.

\section{Conclusions}

We found high variability in linezolid serum concentrations with mostly insufficient low levels in critically ill patients. We therefore suggest general TDM of linezolid in critically ill patients during linezolid therapy. However, future studies will have to investigate whether application of TDM can definitely improve linezolid-dosing protocols and infectionrelated patient outcome.

\section{Key messages}

- High variability of linezolid serum concentrations after standard linezolid dosing in 30 different critically ill patients with suspected infections were observed.
- We observed potentially subtherapeutic levels in the majority of different patients.

- Potentially toxic levels were observed in a minority of different patients.

- Our data suggests that therapeutic drug monitoring might be helpful for adequate dosing of linezolid in critically ill patients.

\section{Additional files}

Additional file 1: Figure showing study protocol of blood sampling

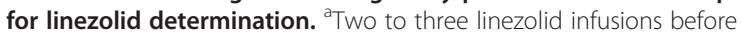
study start with the exception of patients 2 and 27, for whom the study start was directly before the fifth and fourth linezolid administration, respectively: ${ }^{\mathrm{b}} 26$ to 43 samples per patient.

Additional file 2: Table showing parameters of the continuous renal replacement therapy systems used for each patient in this study.

Additional file 3: Table showing parameters of the extracorporeal lung-assist systems used for each patient in this study.

Additional file 4: Figure showing correlation of linezolid trough level $\left(C_{\min }\right)$ values and concentration time curve over $24 \mathrm{~h}\left(\mathrm{AUC}_{24}\right)$ values of linezolid. Shown are values for $\mathrm{AUC}_{24}$ as determined by the NONMEM system from the beginning of the third administration of linezolid, and $C_{\text {min }}$ as determined by liquid chromatography tandem mass spectrometry (LC-MS/MS) directly before the fourth administration of linezolid.

Additional file 5: Figure demonstrating the high variability (inter-patient and intrapatient) of linezolid trough levels $\left(C_{\min }\right)$ over the course of the study for each patient.

Additional file 6: Table showing concentration time curve over $24 \mathrm{~h}\left(\mathrm{AUC}_{24}\right)$ and linezolid trough level $\left(\mathrm{C}_{\mathrm{min}}\right)$ values of patients from the lowest and highest quartile of covariates.

\section{Abbreviations}

APACHE: acute physiology and chronic health evaluation;

$A \cup C_{24}$ : concentration time curve over 24 h; BMl: body mass index;

$C_{\text {min: }}$ linezolid trough level; CRRT: continuous renal replacement therapy; CWH: continuous venovenous hemofiltration; CWHD: Continuous venovenous hemodialysis; CWHDF: continuous venovenous hemodiafiltration; ECLA: extracorporeal lung assist; HPLC-UV: high performance liquid chromatography with UV-detection; LC-MS/MS: liquid chromatography tandem mass spectrometry; MIC: minimal inhibitory concentration; MRSA: methicillin-resistant Staphylococcus aureus; SCCM/ESICM: Society of Critical Care Medicine/European Society of Intensive Care Medicine; TDM: therapeutic drug monitoring; VRE: vancomycin-resistant enterococci.

\section{Competing interests}

The authors declare that they have no competing interests.

\section{Authors' contributions}

$M Z$ and JZ designed the study and wrote the manuscript; BM measured antibiotic concentrations by LC-MS/MS; CN and GD were responsible for acquisition of data; $\mathrm{DN}$ and $\mathrm{CH}$ performed the statistical analyses; $\mathrm{LMH}, \mathrm{MB}$, TW, BG, LF, DT and MV made substantial contributions to the conception and design of the study including interpretation of results. All authors critically revised the manuscript for important intellectual content and approved the final manuscript. All authors meet key authorship requirements and agree to be accountable for all aspects of the work in ensuring that questions related to the accuracy or integrity of any part of the work are appropriately investigated and resolved.

\section{Acknowledgements}

We thank Melissa Wilhelmi-Mock for critically reading the manuscript. This study was supported by a Mérieux Research Grant (Institut Mérieux, Lyon, France). The design, collection, analysis and interpretation of data, plus writing and publication of the manuscript were done by the authors without participation or influence from the funding source. 


\section{Author details}

${ }^{1}$ Department of Anesthesiology, Hospital of the Ludwig-Maximilians-University of Munich, Munich, Germany. ${ }^{2}$ Institute of Laboratory Medicine, Hospital of the Ludwig-Maximilians-University of Munich, Marchioninistrasse 15, Munich 81377, Germany. ${ }^{3}$ Department of Clinical Microbiology and Hospital Hygiene, Hospital of the Ludwig-Maximilians-University of Munich, Munich, Germany.

Received: 9 April 2014 Accepted: 23 June 2014

Published: 10 July 2014

\section{References}

1. Angus DC, Linde-Zwirble WT, Lidicker J, Clermont G, Carcillo J, Pinsky MR: Epidemiology of severe sepsis in the United States: analysis of incidence, outcome, and associated costs of care. Crit Care Med 2001, 29:1303-1310.

2. Engel $\mathrm{C}$, Brunkhorst FM, Bone HG, Brunkhorst $\mathrm{R}$, Gerlach $\mathrm{H}$, Grond $\mathrm{S}$, Gruendling M, Huhle G, Jaschinski U, John S, Mayer K, Oppert M, Olthoff D, Quintel M, Ragaller M, Rossaint R, Stuber F, Weiler N, Welte T, Bogatsch H, Hartog C, Loeffler M, Reinhart K: Epidemiology of sepsis in Germany: results from a national prospective multicenter study. Intensive Care Med 2007, 33:606-618.

3. Karlsson S, Varpula M, Ruokonen E, Pettila V, Parviainen I, Ala-Kokko TI, Kolho E, Rintala EM: Incidence, treatment, and outcome of severe sepsis in ICU-treated adults in Finland: the Finnsepsis study. Intensive Care Med 2007, 33:435-443.

4. Martin CM, Priestap F, Fisher H, Fowler RA, Heyland DK, Keenan SP, Longo CJ, Morrison T, Bentley D, Antman N, STAR Registry Investigators: A prospective, observational registry of patients with severe sepsis: the Canadian Sepsis Treatment and Response Registry. Crit Care Med 2009, 37:81-88.

5. Quenot JP, Binquet C, Kara F, Martinet O, Ganster F, Navellou JC, Castelain V, Barraud D, Cousson J, Louis G, Perez P, Kuteifan K, Noirot A, Badie J, Mezher C, Lessire H, Pavon A: The epidemiology of septic shock in French intensive care units: the prospective multicenter cohort EPISS study. Crit Care 2013, 17:R65.

6. Kumar A, Roberts D, Wood KE, Light B, Parrillo JE, Sharma S, Suppes R, Feinstein D, Zanotti S, Taiberg L, Gurka D, Kumar A, Cheang M: Duration of hypotension before initiation of effective antimicrobial therapy is the critical determinant of survival in human septic shock. Crit Care Med 2006, 34:1589-1596.

7. Sandiumenge A, Diaz E, Bodi M, Rello J: Therapy of ventilator-associated pneumonia. A patient-based approach based on the ten rules of "The Tarragona Strategy". Intensive Care Med 2003, 29:876-883.

8. Pea F, Viale P, Furlanut M: Antimicrobial therapy in critically ill patients: a review of pathophysiological conditions responsible for altered disposition and pharmacokinetic variability. Clin Pharmacokinet 2005, 44:1009-1034.

9. Reinhart K, Brunkhorst FM, Bone HG, Bardutzky J, Dempfle CE, Forst H, Gastmeier P, Gerlach H, Grundling M, John S, Kern W, Kreymann G, Krüger W, Kujath P, Marggraf G, Martin J, Mayer K, Meier-Hellmann A, Oppert M, Putensen C, Quintel M, Ragaller M, Rossaint R, Seifert H, Spies C, Stüber F, Weiler N, Weimann A, Werdan K, Welte T, et al: Prevention, diagnosis, therapy and follow-up care of sepsis: 1 st revision of S-2k guidelines of the German Sepsis Society (Deutsche Sepsis-Gesellschaft e.V. (DSG)) and the German Interdisciplinary Association of Intensive Care and Emergency Medicine (Deutsche Interdisziplinare Vereinigung fur Intensiv- und Notfallmedizin (DIVI)). Ger Med Sci 2010, 8:Doc14.

10. Dellinger RP, Levy MM, Rhodes A, Annane D, Gerlach H, Opal SM, Sevransky JE, Sprung CL, Douglas IS, Jaeschke R, Osborn TM, Nunnally ME, Townsend SR, Reinhart K, Kleinpell RM, Angus DC, Deutschman CS, Machado FR, Rubenfeld GD, Webb SA, Beale RJ, Vincent JL, Moreno R, Surviving Sepsis Campaign Guidelines Committee including the Pediatric Subgroup: Surviving sepsis campaign: international guidelines for management of severe sepsis and septic shock: 2012. Crit Care Med 2013, 41:580-637.

11. Winterboer TM, Lecci KA, Olsen KM: Continuing education: alternative approaches to optimizing antimicrobial pharmacodynamics in critically ill patients. Pharm Pract 2010, 23:6-18.

12. Martin GS, Mannino DM, Eaton S, Moss M: The epidemiology of sepsis in the United States from 1979 through 2000. N Engl J Med 2003, 348:1546-1554.

13. Gales AC, Sader HS, Ribeiro J, Zoccoli C, Barth A, Pignatari AC: Antimicrobial susceptibility of gram-positive bacteria isolated in Brazilian hospitals participating in the SENTRY Program (2005-2008). Braz J Infect Dis 2009, 13:90-98.
14. Appelbaum PC: The emergence of vancomycin-intermediate and vancomycin-resistant Staphylococcus aureus. Clin Microbiol Infect 2006, 12:16-23.

15. Rybak MJ, Akins RL: Emergence of methicillin-resistant Staphylococcus aureus with intermediate glycopeptide resistance: clinical significance and treatment options. Drugs 2001, 61:1-7.

16. Cepeda JA, Whitehouse T, Cooper B, Hails J, Jones K, Kwaku F, Taylor L, Hayman S, Shaw S, Kibbler C, Shulman R, Singer M, Wilson AP: Linezolid versus teicoplanin in the treatment of Gram-positive infections in the critically ill: a randomized, double-blind, multicentre study. Antimicrob Chemother 2004, 53:345-355.

17. Arakawa Y, Ike Y, Nagasawa M, Shibata N, Doi Y, Shibayama K, Yagi T, Kurata $\mathrm{T}$ : Trends in antimicrobial-drug resistance in Japan. Emerg Infect Dis 2000, 6:572-575.

18. Alvarez-Lerma F, Palomar Martinez M, Olaechea Astigarraga P, Insausti Ordenana J, Lopez Pueyo MJ, Gracia Arnillas MP, Gimeno Costa R, Seijas Betolaza I: Analysis of treatments used in infections caused by gram-positive multiresistant cocci in critically ill patients admitted to the ICU. Rev Esp Quimioter 2012, 25:65-73.

19. DeRyke CA, Lodise TP Jr, Rybak MJ, McKinnon PS: Epidemiology, treatment, and outcomes of nosocomial bacteremic Staphylococcus aureus pneumonia. Chest 2005, 128:1414-1422.

20. Falagas ME, Siempos II, Vardakas KZ: Linezolid versus glycopeptide or beta-lactam for treatment of Gram-positive bacterial infections: meta-analysis of randomised controlled trials. Lancet Infect Dis 2008, 8:53-66.

21. McKenzie C: Antibiotic dosing in critical illness. J Antimicrob Chemother 2011, 66:25-31.

22. Jiang $H$, Tang RN, Wang J: Linezolid versus vancomycin or teicoplanin for nosocomial pneumonia: meta-analysis of randomised controlled trials. Eur J Clin Microbiol Infect Dis 2013, 32:1121-1128.

23. Di Paolo A, Malacarne P, Guidotti E, Danesi R, Del Tacca M: Pharmacological issues of linezolid: an updated critical review. Clin Pharmacokinet 2010, 49:439-447.

24. Dryden MS: Linezolid pharmacokinetics and pharmacodynamics in clinical treatment. J Antimicrob Chemother 2011, 66:7-15.

25. Slatter JG, Stalker DJ, Feenstra KL, Welshman IR, Bruss JB, Sams JP, Johnson MG, Sanders PE, Hauer MJ, Fagerness PE, Stryd RP, Peng GW, Shobe EM: Pharmacokinetics, metabolism, and excretion of linezolid following an oral dose of $[(14) \mathrm{C}]$ linezolid to healthy human subjects. Drug Metab Dispos 2001, 29:1136-1145.

26. Pea F, Furlanut $M$, Cojutti $P$, Cristini F, Zamparini E, Franceschi L, Viale $P$ : Therapeutic drug monitoring of linezolid: a retrospective monocentric analysis. Antimicrob Agents Chemother 2010, 54:4605-4610.

27. Stalker DJ, Jungbluth GL: Clinical pharmacokinetics of linezolid, a novel oxazolidinone antibacterial. Clin Pharmacokinet 2003, 42:1129-1140.

28. Gee T, Ellis R, Marshall G, Andrews J, Ashby J, Wise R: Pharmacokinetics and tissue penetration of linezolid following multiple oral doses. Antimicrob Agents Chemother 2001, 45:1843-1846.

29. MacGowan AP: Pharmacokinetic and pharmacodynamic profile of linezolid in healthy volunteers and patients with Gram-positive infections. J Antimicrob Chemother 2003, 51:17-25.

30. Liu C, Bayer A, Cosgrove SE, Daum RS, Fridkin SK, Gorwitz RJ, Kaplan SL, Karchmer AW, Levine DP, Murray BE, J Rybak M, Talan DA, Chambers HF: Clinical practice guidelines by the infectious diseases society of america for the treatment of methicillin-resistant Staphylococcus aureus infections in adults and children: executive summary. Clin Infect Dis 2011, 52:285-292.

31. Rayner CR, Forrest A, Meagher AK, Birmingham MC, Schentag JJ: Clinical pharmacodynamics of linezolid in seriously ill patients treated in a compassionate use programme. Clin Pharmacokinet 2003, 42:1411-1423.

32. Smith PF, Birmingham MC, Noskin GA, Meagher AK, Forrest A, Rayner CR, Schentag JJ: Safety, efficacy and pharmacokinetics of linezolid for treatment of resistant Gram-positive infections in cancer patients with neutropenia. Ann Oncol 2003, 14:795-801.

33. Vinh DC, Rubinstein E: Linezolid: a review of safety and tolerability. J Infect 2009, 59:59-74.

34. Cattaneo D, Orlando G, Cozzi V, Cordier L, Baldelli S, Merli S, Fucile S, Gulisano C, Rizzardini G, Clementi E: Linezolid plasma concentrations and occurrence of drug-related haematological toxicity in patients with gram-positive infections. Int J Antimicrob Agents 2013, 41:586-589. 
35. Whitehouse T, Cepeda JA, Shulman R, Aarons L, Nalda-Molina R, Tobin C, MacGowan A, Shaw S, Kibbler C, Singer M, Wilson AP: Pharmacokinetic studies of linezolid and teicoplanin in the critically ill. J Antimicrob Chemother 2005, 55:333-340.

36. Dong $H$, Wang $X$, Dong Y, Lei J, Li H, You H, Wang M, Xing J, Sun J, Zhu H: Clinical pharmacokinetic/pharmacodynamic profile of linezolid in severely ill intensive care unit patients. Int J Antimicrob Agents 2011, 38:296-300

37. Morata L, Cuesta M, Rojas JF, Rodriguez S, Brunet M, Casals G, Cobos N, Hernandez C, Martinez JA, Mensa J, Soriano A: Risk factors for a low linezolid trough plasma concentration in acute infections. Antimicrob Agents Chemother 2013, 57:1913-1917.

38. Yagi T, Naito T, Doi M, Nagura O, Yamada T, Maekawa M, Sato S, Kawakam $\mathrm{J}$ : Plasma exposure of free linezolid and its ratio to minimum inhibitory concentration varies in critically ill patients. Int J Antimicrob Agents 2013, 42:329-334.

39. Adembri C, Fallani S, Cassetta Ml, Arrigucci S, Ottaviano A, Pecile P, Mazzei T, De Gaudio R, Novelli A: Linezolid pharmacokinetic/pharmacodynamic profile in critically ill septic patients: intermittent versus continuous infusion. Int J Antimicrob Agents 2008, 31:122-129.

40. Boselli E, Breilh D, Rimmele T, Djabarouti S, Toutain J, Chassard D, Saux MC, Allaouchiche B: Pharmacokinetics and intrapulmonary concentrations of linezolid administered to critically ill patients with ventilator-associated pneumonia. Crit Care Med 2005, 33:1529-1533.

41. Swoboda S, Ober MC, Lichtenstern C, Saleh S, Schwenger V, Sonntag HG, Haefeli WE, Hempel G, Hoppe-Tichy T, Weigand MA: Pharmacokinetics of linezolid in septic patients with and without extended dialysis. Eur J Clin Pharmacol 2010, 66:291-298.

42. De Rosa FG, Corcione S, Baietto L, Ariaudo A, Di Perri G, Ranieri VM, D'Avolio A: Pharmacokinetics of linezolid during extracorporeal membrane oxygenation. Int J Antimicrob Agents 2013, 41:590-591.

43. Bodmann KF, Grabein B: Empfehlungen zur kalkulierten parenteralen Intitialtherapie bakterieller Erkrankungen bei Erwachsenen. Update 2010. Chemotherapy J 2010, 19:179-255.

44. Zander J, Maier B, Zoller M, Teupser D, Vogeser M: Quantification of linezolid in serum by LC-MS/MS using semi-automated sample preparation and isotope dilution internal standardization. Clin Chem Lab Med 2013, 52:381-389.

45. Varvel JR, Donoho DL, Shafer SL: Measuring the predictive performance of computer-controlled infusion pumps. J Pharmacokinet Biopharm 1992, 20:63-94.

46. PLT Tools, a graphical interface for the NONMEM system. [http://www.pltsoft.com]

47. Flamm RK, Mendes RE, Ross JE, Sader HS, Jones RN: An internationa activity and spectrum analysis of linezolid: ZAAPS Program results for 2011. Diagn Microbiol Infect Dis 2013, 76:206-213.

48. Flamm RK, Mendes RE, Ross JE, Sader HS, Jones RN: Linezolid surveillance results for the United States: LEADER surveillance program 2011. Antimicrob Agents Chemother 2013, 57:1077-1081.

49. Pea F, Viale P, Cojutti P, Del Pin B, Zamparini E, Furlanut M: Therapeutic drug monitoring may improve safety outcomes of long-term treatment with linezolid in adult patients. J Antimicrob Chemother 2012, 67:2034-2042

50. Carcelero E, Soy D, Guerrero L, Poch E, Fernandez J, Castro P, Ribas J: Linezolid pharmacokinetics in patients with acute renal failure undergoing continuous venovenous hemodiafiltration. J Clin Pharmacol 2012, 52:1430-1435.

51. Meyer B, Kornek GV, Nikfardjam M, Karth GD, Heinz G, Locker GJ, Jaeger W, Thalhammer F: Multiple-dose pharmacokinetics of linezolid during continuous venovenous haemofiltration. J Antimicrob Chemother 2005, 56:172-179.

52. Pea F, Viale P, Lugano M, Pavan F, Scudeller L, Della Rocca G, Furlanut M: Linezolid disposition after standard dosages in critically ill patients undergoing continuous venovenous hemofiltration: a report of 2 cases. Am J Kidney Dis 2004, 44:1097-1102.

53. Fiaccadori E, Maggiore U, Rotelli C, Giacosa R, Parenti E, Picetti E, Sagripant S, Manini P, Andreoli R, Cabassi A: Removal of linezolid by conventional intermittent hemodialysis, sustained low-efficiency dialysis, or continuous venovenous hemofiltration in patients with acute renal failure. Crit Care Med 2004, 32:2437-2442.
54. Stokvis $\mathrm{E}$, Rosing $\mathrm{H}$, Beijnen $\mathrm{JH}$ : Stable isotopically labeled internal standards in quantitative bioanalysis using liquid chromatography/mass spectrometry: necessity or not? Rapid Commun Mass Spectrom 2005, 19:401-407.

55. Kumar A: An alternate pathophysiologic paradigm of sepsis and septic shock: Implications for optimizing antimicrobial therapy. Virulence 2013, 5:80-97.

doi:10.1186/cc13984

Cite this article as: Zoller et al.: Variability of linezolid concentrations after standard dosing in critically ill patients: a prospective observational study. Critical Care 2014 18:R148.

\section{Submit your next manuscript to BioMed Central and take full advantage of:}

- Convenient online submission

- Thorough peer review

- No space constraints or color figure charges

- Immediate publication on acceptance

- Inclusion in PubMed, CAS, Scopus and Google Scholar

- Research which is freely available for redistribution

Submit your manuscript at www.biomedcentral.com/submit
C) Biomed Central 